\title{
Perceptions, Attitudes and Practices on Achistosomiasis in Delta State, Nigeria
}

\author{
NKECHI G. ONYENEHO ${ }^{7 * 1}$, PAUL YINKORE ${ }^{2}$, JOHN EGWUAGE ${ }^{3}$ and EMMANUEL EMUKAH ${ }^{4}$ \\ ${ }^{I}$ Department of Sociology/Anthropology, University of Nigeria, Nsukka, Enugu State, Nigeria \\ ${ }^{2}$ Ministry of Health, Asaba, Delta State, Nigeria \\ ${ }^{3}$ Carter Center, Edo/Delta, Benin City, Nigeria \\ ${ }^{4}$ Carter Center, Jos, Nigeria, Nigeria
}

\begin{abstract}
Urinary schistosomiasis, which is one of the commonest forms of the parasitic disease is a major debilitating disease characterized by blood in urine. The main objective of the study reported here was to assess the knowledge, attitude/perception and practices of the people in Oshimili South and Ndokwa Northeast Local Government Areas of Delta State in Nigeria. A cross-sectional study of 400 randomly selected persons aged $\geq 15$ years was undertaken using a uniform set of structured interview schedule administered by trained field assistants. This was supported with some qualitative data collected from in-depth interview with community leaders and school teachers as well as focus group discussions with community members. One-third of the people interviewed were aware of the schistosomiasis. For a majority however, the perceived causes of the disease included witchcraft and sexual or body contact with infected persons. For some of the respondents, the disease is not serious since it does not harm or prevent the victim from eating. In many cases the disease was not treated because of the belief that there is no effective cure for it and that it reoccurs after treatment. But perhaps more importantly, the infection is not treated because it is considered a normal growing up process, which the infected person outgrows. A very high proportion of people depended on the schistosomiasis-infected river for all the domestic needs even where there are alternative sources of water. People argued that the river/ stream give them purer water than the hand dug wells. Furthermore, swimming is a popular activity in the river during all seasons, irrespective of sex and age. In conclusion, the study has identified gaps in the knowledge of the cause and means of transmission, poor perception and management practices, which calls for systematic health education on schistosomiasis in the communities
\end{abstract}

Key words: urinary schistosomiasis, knowledge, attitude, perception, practice, Nigeria

\section{Introduction}

Urinary schistosomiasis is a major debilitating disease characterized by blood in the urine. In the worst cases urinary schistosomiasis will cause bladder cancer. It is caused by Schistosoma haematobium and about 38 million people are infected in 16 African countries (WHO, 1985). According to Anosike et al. (2001), Nigeria is one of the highly endemic countries where the disease has been unsystematically reported and large areas remain where the disease status is unknown. Schistosomiasis spreads through the direct contamination of water by an infected person urinating into the water. This happens for two main reasons. People unknowingly contaminate their environment because of a lack of education.

\footnotetext{
* Correspondence: Nkechi Onyeneho; E-mail: nkechux@yahoo.com
}

Another reason is an insufficient attention to hygiene. Schistosomiasis is associated with poverty and poor living conditions, inadequate sanitation, and poor water supply as well as unplanned water resource development. Inadequate knowledge, attitude/perception and improper practice in relation to schistosomiasis contribute to maintain schistosomiasis at a high level of prevalence. Schistosomiasis has an impact on the overall health status and fitness of schoolchildren (Nwaorgu et al., 1998). Apart from the morbidity associated with acute infections, they affect the physical fitness (Stephenson et al., 1990), cognitive performance (Connolly \& Kvalsig, 1992), nutritional status and growth (Stephenson, 1994) and school attendance (Nokes \& Bundy, 1993) among school-aged children.

The distribution of urinary schistosomiasis (Schistosoma haematobium in Nigeria was explored in a survey, conducted in 1990-91, that showed that 
infection was most prevalent in the north-central and southeast areas of the country (Hopkins et al., 2002). However, a recent survey by The Carter Center, Nigeria revealed that parts of the Niger Delta, especially Delta State are also endemic.

The potential problems associated with poor education regarding schistosomiasis further highlight the need for a community training and health education campaign before and during an intervention programme. But, health education interventions have often failed in the past. Some researchers conclude that promoting behavioural changes obscures underlying structural and political problems associated with diseases and is tantamount to victim blaming, while research from the last decade have shown that health promotion interventions failed because they were designed without knowledge of the health behaviour of the target population (Godin \& Shepard 1983). This survey was needed to design the health education aspect of a schistosomiasis control program planned by the Ministry of Health $(\mathrm{MoH})$ and the Carter Center for Delta State.

This paper presents results on the knowledge attitude/perception and practices of the people of Delta State on schistosomiasis. It aimed at the exploration and description of the knowledge, attitude and practice of the community members with regards to schistosomiasis in two LGAs in Delta State, Nigeria.

\section{Materials and Methods}

\section{Study area and population}

The study was carried out in Delta State, Nigeria. Delta State $\left(5^{0} 30^{\prime} \mathrm{N} ; 6^{0} 00^{\prime} \mathrm{E}\right)$ is located in the south geopolitical and oil rich zone of Nigeria and is made up of 25 LGAs. It is generally low lying with wide coastal belt interlaced with rivulets and streams which form the Niger Delta and which make good habitat for many water-borne and water related diseases. The State is endemic with soil-transmitted helminthes, schistosomiasis, lymphatic filariasis and onchocerciasis. The LGAs where the existence of schistosomiasis has been confirmed through a prevalence survey conducted by The Carter Center constituted the focus of the study. These are Ndokwa East and Oshimili South LGAs, located on the banks of River Niger. Based on the 1991 population census, the population of Ndokwa-East and Oshimili South LGAs was projected at 104,203 and 87,889 respectively in 2003 . The study focused on persons aged $\geq 15$ years who were capable of articulating coherent responses to the issues raised in the study. This segment constituted about 53\% of the total population of the different LGAs.

\section{Study design, size and sampling technique}

This was a cross-sectional descriptive study which integrated quantitative and qualitative techniques such as focus group discussions and in-depth interviews. While the quantitative data provided opportunity for statistical measurement of observations aimed at characterizing the study subjects, the qualitative data provided in-depth contextual data to the quantitative data.

Four hundred respondents, 200 each from Ndokwa East and Oshimili South LGAs respectively, constituted the sample for the quantitative study. This number was considered sufficient to support the simple descriptive statistics required for this situation analysis study. A multi-stage sampling technique, which involved successive random sampling to pick communities, villages and individual respondents, was adopted in drawing the sample. First the schistosomiasis endemic communities were listed and one community selected from each of the LGAs through balloting. Four villages were selected through balloting from each of the communities. In Oshimili South LGA, Oko community, which is largely meso-endemic was sampled. Four mesoendemic villages, namely Oko-Amakom, OkoOdifulu, Oko-Ogbele and Ukwuadu were randomly selected from the list of villages in the community. In Ndokwa East, three hyper (Abuator, Lagos Iyede, Obodo-Oyibo Okpa) and one meso-endemic (Umuonya Aboh), villages were randomly selected from Aboh community. Each sampled village was assigned fifty respondents.

To get the respondents in each sampled village, the existing registers for the distribution of ivermectin was employed. From the register, systematic sampling of households was carried out for each village. From the sampled household one person, one male or one female aged $\geq 15$ years was randomly selected. Efforts were however made to ensure a balanced representation of the sexes in the sample by alternating the sexes of persons selected from the households. That is, in the sampled households, lists were compiled of the female members different from those of the males in the households. Where there is only one person with the required attribute, the qualified person was purposively selected.

In addition to this, some members of the community, who were not involved in the quantitative study, were purposively selected for the qualitative study. The criteria for selection varied 
with the nature of the qualitative study. For instance, the community/traditional leaders, health facility personnel and head teachers of the community schools were purposively selected for in-depth interviews. Some members of the community, who were not involved in either the quantitative study, were selected on the basis of availability for the focus group discussions.

\section{Data collection}

The major instrument for the purpose of collecting data for the study was the structured questionnaire. However, some qualitative data were ensured through the use of focus group discussions (FGDs) and in-depth interviews (IDIs). This was considered necessary to give some contextual meaning to the quantitative findings in the study.

For the quantitative data, a uniform set of questionnaire was administered to all the respondents irrespective of sex and location. The questionnaire sought information on the sociodemographic (background) characteristics of the respondents, knowledge, attitude and practice on schistosomiasis. It also collected data on their water contact activities as well as environmental sanitation. The FGDs and in-depth interviews were conducted with carefully developed FGD/ in-depth interview guide, which contained diagnostic questions on some of the issues raised in the questionnaire study. This provided in-depth understanding on the socio-cultural risk factors of the people with respect to issues that affect the transmission and control of schistosomiasis. For the qualitative data, FGDs were conducted with 6-8 persons in a group. The discussions were held with adult males and females, aged 25-35 years and adult males and females aged $\geq 36$ years. Discussions were also held with young males and females aged 15-24 years as well as with young persons of school age in the communities. A total of twelve FGDs, six per LGA, were conducted in all. This gave at least two per category of discussants and ensured collaborative information.

The participants in the FGDs were purposively selected from persons within the age and sex groups described above, who were not interviewed in the questionnaire study. To ensure this, new villages within the communities were randomly selected for the FGDs. Same sex discussion groups were ensured. A note-taker was also on hand to record important non-verbal expressions and reactions to issues raised by the facilitators of the FGDs. The discussions were tape recorded and notes also taken.
To ensure uniformity in the interpretation of concepts and recording of responses, the questionnaire was administered inface-to-face (otheradministered) interviews with all the respondents. For this purpose, field assistants were recruited and trained on the objectives and methods of the study. Same sex interviews were conducted to prevent any cultural barriers and ensure free discussion of issues. This is considered important with sensitive issues like illness and disease conditions that locally conjure stigmatization and sensitivity (Scott \& Singh, 1981; Obikeze \& Okeibunor, 2002). The interviews were tape recorded.

\section{Data analysis}

Data editing and validation was done on a daily basis, starting from the field and on return from the field to ensure that problems are detected as early as possible when it will still be possible to apply corrective measures. All data were double entered into two computers by data entry clerks. Two separate files were created. Analysis of the qualitative data placed emphasis on the interpretation, description and recording/writing of what was actually said. The transcripts were first done in the local language, translated into English and retranslated into the local language to ensure that the English and Local language versions carried the same meanings. In going through the transcriptions, phrases with contextual or special connotations were noted and pulled out as illustrative quotes in complimenting the statistical data. To do this, relevant themes were developed for the coding and sorting of the qualitative data.

The questionnaire data were computer processed and analyzed using the EPI6 and SPSS software packages for data analysis. Percentages and other descriptive statistics as well as graphic illustrations were used to describe the main characteristics of the study subjects. The Chi-square $\left(\mathrm{c}^{2}\right)$ statistics was used to test the association of the characteristics of the respondents with activities that promote the transmission of schistosomiasis in the communities. The data from the in-depth interviews and FGDs were analyzed with the inductive techniques with emphasis on interpretation and description of what was actually said. Some of the instructive statements were pulled out as illustrative quotes to support or give contextual meaning to the statistical data.

\section{Ethical consideration}

The study received scientific and ethical clearance from the State Ministry of Health. The community 
leaders gave consent for the study on behalf of the community members. This was necessary as part of the community entry process. In addition, the content of a consent note with all information about the study was read out to those selected to participate in the study and approval sought before the actual data collection commenced.

\section{Results}

Socio-demographic characteristics of respondents The age range was from $15-89$ years (mean $=40.6 \pm$ 18.9 years). The modal and median ages were 30 years and 37 years respectively. The age interval $\geq 65$ years accounted for the largest proportion (16.0\%) of respondents. About half (49.8\%; N=199) of the respondents were males while the remainder of 291 $(50.2 \%)$ was females. The majority $(63.3 \%)$ of the respondents were into peasants/wine tappers. About a third $(33.7 \%)$ had no formal education. Another $44.5 \%$ had only first school leaving certificate. A total of 874 school age persons were recorded in the households visited. About two-thirds (63.6\%) of these were in school, $17.4 \%$ had dropped out of school while $19.0 \%$ never went to school.

Table 1: Distribution of Respondents by Awareness/knowledge on Schistosomiasis

\begin{tabular}{|c|c|c|c|}
\hline Variable & Response & Frequency & Percentage \\
\hline \multirow[t]{3}{*}{ Signs/Symptoms } & Emaciation & 43 & 31.9 \\
\hline & Passing blood in urine & 120 & 88.9 \\
\hline & Poor Health & 28 & 21.1 \\
\hline \multirow[t]{6}{*}{ Causes } & Maturity & 2 & 1.5 \\
\hline & Dirty water & 102 & 75.6 \\
\hline & Witch craft & 9 & 6.7 \\
\hline & Worm in body & 8 & 5.5 \\
\hline & Eating unripe fruit & 5 & 3.7 \\
\hline & Animals & 3 & 2.6 \\
\hline \multirow[t]{8}{*}{ How it is contracted } & Body contact with an infected person & 9 & 6.7 \\
\hline & Sexual contact & 18 & 13.3 \\
\hline & Crossing somebody's urine & 22 & 16.3 \\
\hline & & 14 & 10.4 \\
\hline & Crossing somebody's faeces & 64 & 47.4 \\
\hline & Walking across water & 61 & 45.2 \\
\hline & Swimming in water & 61 & 45.2 \\
\hline & Drinking bad water & & \\
\hline \multirow[t]{6}{*}{ How it is transmitted } & By walking across water & 46 & 43.1 \\
\hline & Through mosquito bite & 9 & 6.7 \\
\hline & Through blood transfusion & 7 & 5.2 \\
\hline & Through snails in water & 38 & 28.1 \\
\hline & By urinating in water & 47 & 34.8 \\
\hline & Sexual contact with infected person & 9 & 7.7 \\
\hline \multirow[t]{8}{*}{ Consequences } & Weak bladder & 23 & 17.0 \\
\hline & Loss of protein & 24 & 17.8 \\
\hline & Infertility & 18 & 13.3 \\
\hline & Blocking of bladder & 14 & 10.4 \\
\hline & Anal itching & 16 & 11.9 \\
\hline & Blocking of intestine & 9 & 6.7 \\
\hline & Sterility & 18 & 13.3 \\
\hline & Blood in urine & 43 & 31.9 \\
\hline \multirow[t]{7}{*}{ Prevention } & Not urinating in or near body of water & 26 & 19.3 \\
\hline & Avoid mosquito bite & 10 & 7.4 \\
\hline & Avoid blood transfusion & 10 & 7.4 \\
\hline & No swimming through water & 36 & 26.7 \\
\hline & Not walking through water & 28 & 20.7 \\
\hline & Avoid contact with infected person & 10 & 7.4 \\
\hline & $\begin{array}{l}\text { Avoid sexual contact with infected } \\
\text { person }\end{array}$ & 12 & 8.9 \\
\hline
\end{tabular}




\section{Knowledge}

The study communities had varying levels of knowledge of schistosomiasis and local names describing the manifestations of the disease. There is a very poor level of knowledge of the disease among the Oko people. In Ukwuadu, the community members in various FGD sessions indicated ignorance of the disease until officials from the Ministry of Health carried out investigation using school age children in the community. According to the village head, "We did not know anything about the disease. It was only when the ministry people came and took samples of urine from school children they confirmed that the disease is here. They showed it to us". Another community member from Oko Ogbele in an FGD said "I am not surprised because we live in a very bad condition here. As you can see, there can be many types of diseases. When we were told I believed because you always find the boys scratching their genitals. We suspected nothing then"

Table 2: Distribution of respondents by factors associated with awareness on schistosomiasis (\%in

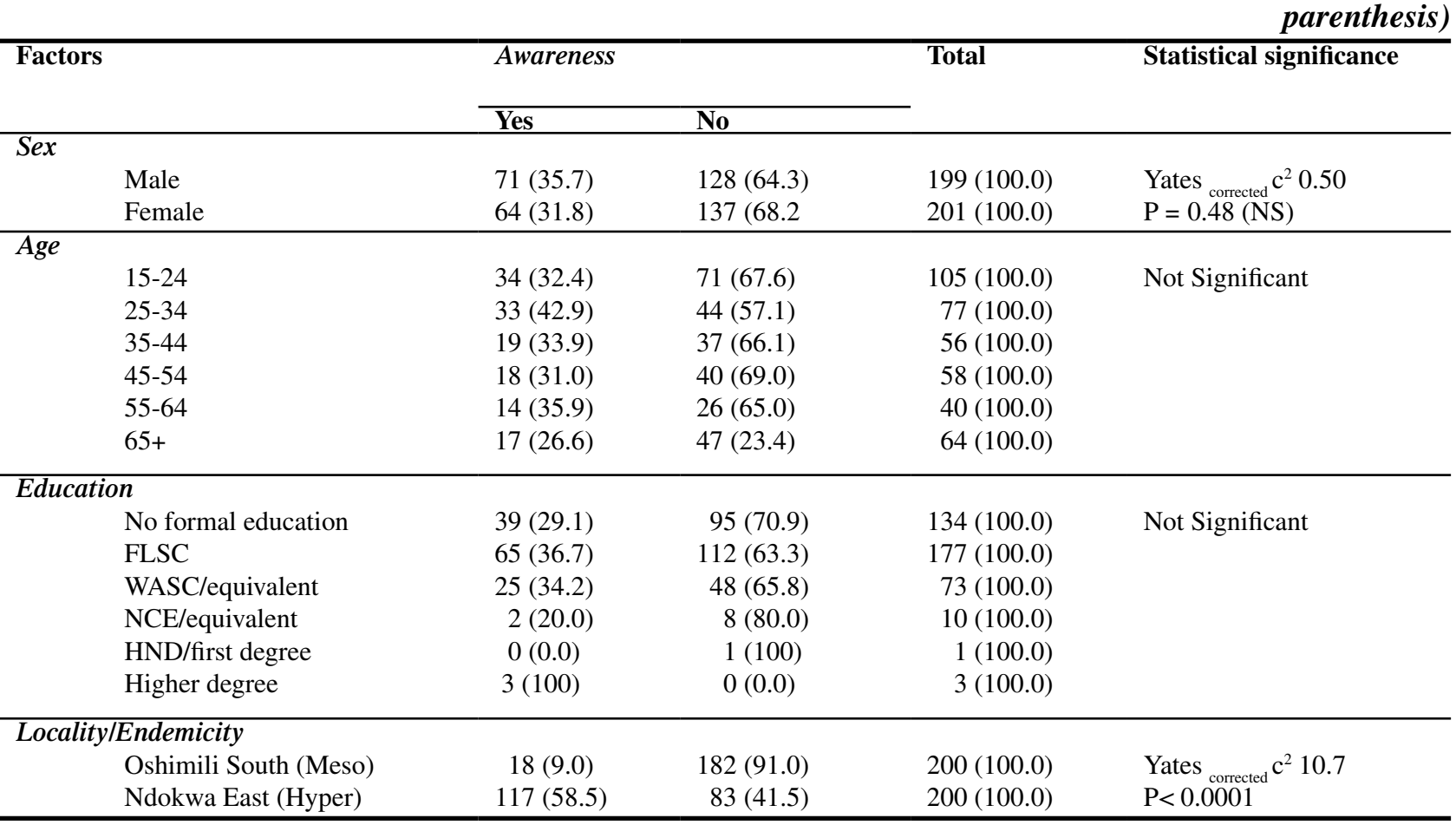

These were typical of the views expressed by respondents to questions on the awareness of the disease during in-depth interviews as well as contributions to discussions about the same issue in FGDs involving both sexes and people of the different age groups in Oko community, which is meso endemic. They had no name for the disease, because most of the people were only recently beginning to be aware of it as a disease condition to worry about. However, in Ndokwa East LGA, where the communities are hyper endemic, the knowledge of the disease was high compared to the Oko community. In Ndokwa East LGA, different terms were used as local names for the disease, these included "emu mmamiri", "mmamiri edeke" or "emu ukwu", meaning urine disease, bloody urine or waist disease to depict the pain it causes the victim around the waist while urinating.
One-third $(33.8 \%)$ of the respondents indicated awareness of the disease. This includes both the prompted and unprompted responses. A total of 62 respondents made unprompted mention of the disease as one of the five important problems in the communities. It was however rated differently in relation to other health problems. Sixteen $(26.0 \%)$ of this category of respondents rated it the first most important problem while $18 \%$ rated it as the $5^{\text {th }}$ most important problem in the communities.

The signs/symptoms of the disease indicated by the 135 respondents who indicated awareness of the disease include emaciation and general poor health. A large proportion of the respondents indicated passing of blood in urine as a symptom. Dirty water was mentioned by $75.6 \%$ of the respondents as the cause for the disease. Others causes listed include witchcraft $(6.7 \%)$, which contained the next highest proportion of causes 
mentioned. Two respondents, from this category of respondents, described it as a process of transition into maturity while some (2.6) associated it with the presence of some animals in the community. This is similar to the contention in an FGD session with adult women in Obodo-Oyibo Okpai community where it was argued that it is caused by goats. According the one of the participants "They say it is goat that brought it. It is when you cross goat urine you get it. In our neighboring community they suffered it in the past and they legislated against keeping goats in the community and that was how they eliminated it from their community". Another contended that " it is the civil war that brought the illness". These were among the several ways of contracting and transmitting the disease listed in the responses to the questionnaire items. Some perceive it as a sexually transmitted disease while others indicated that it is transmitted through body contact with an infected person.

The perceived consequences of the disease include infertility and sterility mentioned by $13.3 \%$ respectively. Others include weak bladder (17.0\%), blood in urine (31.9\%) and anal itching (11.9\%) among others. The most popular way of preventing it is 'no swimming through water' $(26.7 \%)$, 'not walking through water' $(20.7 \%)$ and 'not urinating in or near body of water' (19.3\%) (Table 1).

There was no significant difference in the level of awareness of schistosomiasis among the different age groups even though more (42.9\%) of the persons aged 25-34 years demonstrated awareness as against those in the older age group of $\geq 65$ years with 26.6\%. Similarly, the sex of the respondents was not statistically significant in predicting awareness of the respondents on schistosomiasis. Slightly more of the male respondents (35.7\%) than the female respondents (31.8\%) were aware of the schistosomiasis. The Yates ${ }_{\text {corrected }} \mathrm{c}^{2}$ value of 0.50 however revealed that this difference is not statistically significant. On the other hand, locality and endemicity levels showed significant influence on the level of awareness among the respondents. A very large proportion (58.5\%) of those from Ndokwa east LGA, with hyper endemic communities showed awareness for the disease. Only 18 (9.0\%) of those from Oshimili South with predominantly meso endemic communities were aware of the disease. This difference was shown to be statistically significant $(\mathrm{P}<0.0001)$ (Table 2).

\section{Attitude and belief towards schistosomiasis}

The respondents hold different attitude towards the infection with schistosomiasis. A majority $(84.4 \%)$ of the respondents regards the infected person as one who is not healthy. Some $(10.4 \%)$ however, considered the infected person as healthy while 7 $(5.2 \%)$ of the respondents, who indicated awareness of the disease could not classify the infected person as health or not healthy. When asked how serious schistosomiasis in their communities is, $52.6 \%$ considered it very serious while $33.3 \%$ described it as only serious. Some 10.5 and $3.5 \%$ considered the disease as not serious and like any other ill health, respectively.

Table 3: Distribution of Respondents on Agreement/disagreement on Schistosomiasis (\% in Parenthesis)

\begin{tabular}{lrrr}
\hline Statement & Agree & Disagree & Don't Know \\
& & & \\
\hline a) Schistosomiasis infection is normal growing up & $29(21.6)$ & $95(70.9)$ & $10(7.5)$ \\
b) There is no need bothering to treat it & $14(10.4)$ & $120(88.9)$ & $1(0.7)$ \\
c) One outgrows schistosomiasis & $22(16.5)$ & $98(73.7)$ & $13(9.8)$ \\
d) Schistosomiasis infection reoccurs & $63(46.7)$ & $61(45.2)$ & $11(8.1)$ \\
e) Schistosomiasis is part of life & $26(19.5)$ & $95(71.4)$ & $12(9.0)$ \\
f) It is a disease for males & $13(9.8)$ & $111(84.1)$ & $8(6.1)$ \\
g) It is sexually transmitted disease & $34(25.8)$ & $81(61.4)$ & $17(12.9)$ \\
h) It affects marital life & $50(37.6)$ & $66(49.6)$ & $17(12.9)$ \\
i) It is better treated with herbs & $31(25.8)$ & $78(65.0)$ & $11(9.2)$ \\
j) It is better treated with pharmaceutical drugs & $114(88.4)$ & $11(8.5)$ & $4(3.1)$ \\
\hline
\end{tabular}

Furthermore, about half (52.6\%) of the respondents considered schistosomiasis a very serious infection while just a third (33.3\%) thought it is just serious. One in every ten persons, who indicated awareness of the disease, regarded the disease as 'not serious'.
The qualitative component of the study produced similar results. A typical logic was captured in the expression of the village chairman of Abuator community, who thinks it is not a serious problem. According to him, "It is not serious because it does 
not make them (the infected persons) to lie down or prevent them from eating food. It does not harm the child. It gives no problem only that when you see such a thing you will be afraid. I don't know anything about it but I know it is not sexually transmitted disease because it also affects children"

Some young men in an FGD session in Obodo-Oyibo Okpai, thought it is not serious because according to them, "It is a normal thing. Any growing child will get it". Similarly, the young girls in Obodo-Oyibo Okpai, argued that, "One can outgrow the infection"

A large proportion (88.4\%) of the respondents was of the view that it is better treated with pharmaceutical drugs. About a quarter of the respondents however thought it is better treated with herbs $(25.8 \%)$. In an in-depth interview with the community leader for Oko Amakom, it was indicated that the treatment was not known. According to him, "We do not know how to treat blood in urine. But if it is oria ukwu (waist disease) take injection... use herbs"

Some respondents show poor knowledge and attitude by agreeing with some misconceptions on schistosomiasis (Table 3). For instance it is believed by some of the respondents that schistosomiasis infection has no effective treatment and does reoccur. Others think one can only outgrow it while others hold the belief that it is disease for the males only.

Respondents were asked to score on a scale of 1-3 for their levels of agreement with 7 different statements that were obvious untrue about schistosomiasis. The statements are items a- c, e-g and i on Table 3. For each issue, the scores for the related statements were combined into one indicator, ranging from 7 for complete agreement to 14 for complete disagreement and 21 for complete uncertainty. These were further categorized into an index of 'very poor' attitude (1) where there is complete agreement with the misconceptions; 'good' for complete disagreement (2) and 'not good' for complete uncertainty (3). The different combination of agree, disagree and uncertainty thus gave a range of such attitude towards schistosomiasis. The results showed that the male respondents were clearly negative in their attitude towards schistosomiasis. The male respondents indicated their agreement with the ideas that suggest a misconception about schistosomiasis. Half of the male respondents indicated agreement with a median score of 1 point, which indicated full agreement on all seven items to measure the degree of misconception. The remaining half showed different degrees of acceptance of these misconceptions.

On the other hand, half of the female respondents disagreed with the seven statements presenting the misconception of schistosomiasis. The remaining half however exhibited different levels of agreement with these misconceptions. The female respondents made a median score of 2 points showing more disagreement with the misconceptions. Different levels of agreement with the misconceptions were noticed across the different age groups. The younger age groups show greater disagreement with the ideas, which constitute misconceptions with schistosomiasis. With a median of 2.0, half of the younger populations aged 54 years and below disagreed fully with such ideas. However, a majority of the older populations scoring between 1.0 and 1.5 showed stronger agreement with the statements.

No clear pattern is discernable with respect to the level of education attained by the respondents. Those with no formal education were evenly divided between full agreement and disagreement with the ideas about misconceptions on schistosomiasis, $50 \%$ of those with primary education agree, 25 per cent disagree while the remaining $25 \%$ indicated total uncertainty. While those with NCE/OND betrayed total uncertainty about these issues, those with higher degrees spread out evenly between total agreement with the issues through total agreement and uncertainty about the issues.

Table 4: Distribution of Respondents by Practices on Schistosomiasis Infection

\begin{tabular}{llll}
\hline Variable & Response & Frequency & Percentages \\
\hline Household member infected? & Yes & 87 & 64.4 \\
& No & 48 & 35.6 \\
\hline \multirow{2}{*}{ Know anyone infected in the community? } & Yes & 30 & 63.8 \\
& No & 17 & 36.2 \\
\hline \multirow{2}{*}{ Where was it treated? } & Patent medicine store & 16 & 13.7 \\
& Clinic & 7 & 6.0 \\
& Hospital & 35 & 29.9 \\
& Herbalist & 8 & 6.8 \\
\hline
\end{tabular}




\begin{tabular}{lllr}
\hline Variable & Response & Frequency & Percentages \\
\hline \multirow{3}{*}{ Category of persons most affected } & Male & $\mathbf{6 2}$ & 81.6 \\
& Female & $\mathbf{1 4}$ & 18.4 \\
& Children & $\mathbf{8 4}$ & 80.8 \\
& Adolescent & $\mathbf{1 0}$ & 9.6 \\
& Adult & $\mathbf{1 0}$ & 9.6 \\
\hline \multirow{3}{*}{ Occupation } & School pupils & $\mathbf{5 7}$ & 66.3 \\
& Farmers & $\mathbf{1 1}$ & 12.8 \\
& Fishers & $\mathbf{1 6}$ & 18.6 \\
\hline
\end{tabular}

\section{Practices on schistosomiasis infection in endemic communities}

About two thirds $(64.4 \%)$ of the respondents, who indicated awareness of the disease also indicated that it has affected members of their household. Furthermore, $63.8 \%$ of those, who have not witnessed it in their households, indicated that they have seen the victims in their communities (Table 4). This shows the pervasiveness of the disease among those who are aware of it. The qualitative data show claims of such experiences among the community members. All the same, the community leader for Oko Amakom argued that, "I have never seen a person who passed blood in urine because you do not go inspecting urine passed by people. But I know some people who have sexually transmitted diseases, which we call oria ukwu" (waist disease). In the same vein, some men in an FGD session in Abuator community said, "There are many children that have it in this community. At times it will be scratching them and they will hold their penis". Another participant in the FGD session said, "Sometimes I have it. My children have it but I do not feel it is illness" To this suggestion, a female participant in an FGD session countered, "For my own sickness is sickness. No illness is small. The only way to prevent it is if those who know more than us come to our aid".

A community leader in Obodo-Oyibo Okpai said he has seen people infected with the disease. According to him, "The disease attacked many of the youth. It is a general sickness. Even people our ages were attacked" Some school age children from Abuator community, said in an FGD session that, "We know it is sickness. It affects everyone in this community; even mature people urinate blood. Nothing is done about it. No medicine to cure it". However, the young men in Obodo-Oyibo Okpai argue that it only affects little children in their community, which is hyper endemic with the disease. Another member of the group stressed that, "Many of them, (the children) will be crying when they want to piss. It can cause fever and waist pain to children. Na serious problem but I am not sure it has any permanent treatment for it. They take some drugs. The drugs are mixed together". These are reflections of the people's knowledge of the disease. This also introduces the idea of their practices about the disease. Most respondents did not treat the infection until the recent campaign by the Ministry of Health officials (43.6\%) (Table 4). Just before this baseline survey, and following the prevalence survey, the Carter Center and Ministry of Health organized treatment for children in the endemic communities. Thus for this segment the infection was not treated until the intervention effort by Carter Center/Ministry of Health.

Among those who sought some form of treatment, 6.8 per cent indicated that treatment was sought with herbalists. Some $13.7 \%$ indicated that treatment was sought with patent medicine vendors. Seven $(6.0 \%)$ indicated that treatment was sought in clinic while $29.9 \%$ indicated hospitals as the place to seek treatment for the infection. But there seem to be very little faith in the treatment from patent medicine vendors and hospitals. According to a young man in Obodo-Oyibo Okpai, "Many go to Chemist and Hospital. They give them injection. After two weeks the thing (the disease) will come again. Some people will write drugs for them to drink. The drugs are not effective".

Generally, it is believed that the infection is more among males and children. Four in every five persons, who have experienced it interviewed, indicated that it more in males and children with $81.6 \%$ and $80.8 \%$, respectively. Among the occupation group most at risk, 66.3 per cent of the respondents indicated school pupils. Explaining the reason why it is most common in children and school pupils in particular, an adult male argued that, "The children swim too much in the stream. The children go to the stream than the elders".

With respect to sex differentials, there was a general belief that the disease is more in the 
males than females. Eight in every ten persons, who responded to the question on any sex differential in the infection (80.8\%), indicated that it is more in the males. The FGD sessions however contradicted this and reasons were adduced on why it is believed to be a male disease. According to a participant in an FGD session in Abuator, "It is more common in males. Women have a way of easing themselves. You cannot know when and if they have the problem. But for the males you can see them urinating with difficulty". The school children from Obodo-Oyibo
Okpai contend that the disease knows no sex barrier, when they chorused that, "It has happened to us both boys and girls". A lady in the FGD with adolescent girls in Obodo-Oyibo Okpai gave a reason she perceives as the factor responsible for the perceived sex difference in the rate infection when she said that, "When the people from the Ministry came for the prevalence survey, the young girls present were only submitting their initial urine. They hid the last, which comes with blood.... It is shame that make people to hide the sickness"

Table 5: Distribution of respondents by water contact activities (\% in parenthesis)

\begin{tabular}{|c|c|c|c|c|c|c|}
\hline Activities During Rainy Season & $\begin{array}{l}\text { River/ } \\
\text { stream }\end{array}$ & Lake & Pond & Well & $\begin{array}{l}\text { Pipe borne } \\
\text { water }\end{array}$ & $\begin{array}{l}\text { Rain water } \\
\text { (Harvested) }\end{array}$ \\
\hline Drinking & $170(42.7)$ & $14(3.5)$ & $29(7.3)$ & $2(0.5)$ & $32(8.0)$ & $258(64.8)$ \\
\hline Cooking & $209(52.5)$ & $13(3.3)$ & $33(8.3)$ & $5(1.3)$ & $18(4.5)$ & $178(43.5)$ \\
\hline $\begin{array}{l}\text { Washing cassava, vegetable, fruits and } \\
\text { other farm products }\end{array}$ & $266(66.8)$ & $13(3.3)$ & $33(8.3)$ & $3(0.8)$ & $13(3.3)$ & $105(26.4)$ \\
\hline Washing utensils/clothes & $270(67.8)$ & $13(3.3)$ & $32(8.0)$ & $3(0.8)$ & $14(3.5)$ & $106(26.6)$ \\
\hline Bathing & $263(66.1)$ & $14(3.5)$ & $41(10.3)$ & $3(0.8)$ & $15(3.8)$ & $96(24.1)$ \\
\hline Swimming & $294(73.9)$ & $15(3.8)$ & $40(10.1)$ & -- & -- & -- \\
\hline \multicolumn{7}{|l|}{ Activities During Dry Season } \\
\hline Drinking & $310(77.7)$ & $29(7.3)$ & $43(10.8)$ & $6(1.5)$ & $29(7.3)$ & $15(3.8)$ \\
\hline Cooking & $318(79.7)$ & $29(7.3)$ & $41(10.3)$ & $5(1.3)$ & $16(4.0)$ & $5(1.3)$ \\
\hline $\begin{array}{l}\text { Washing cassava, vegetable, fruits and } \\
\text { other farm products }\end{array}$ & $321(80.5)$ & $29(7.3)$ & $42(10.5)$ & $5(1.3)$ & $14(3.5)$ & $3(0.8)$ \\
\hline Washing utensils/clothes & $323(81.0)$ & $29(7.3)$ & $41(10.3)$ & $4(1.0)$ & $17(4.3)$ & $3(0.8)$ \\
\hline Bathing & $324(81.2)$ & $29(7.3)$ & $40(10.0)$ & $5(1.3)$ & $15(3.8)$ & $1(0.3)$ \\
\hline Swimming & $322(80.7)$ & $30(7.5)$ & $39(9.8)$ & -- & -- & -- \\
\hline
\end{tabular}

\section{Water contact activities}

The communities depended heavily on the river/ stream, lake and ponds for household water requirements especially in the dry season. Even in the rainy season more than five in every ten persons interviewed depended on the river/stream for such household water needs like cooking, washing farm products, washing utensils/clothes, bathing and swimming. Only the water for drinking needs is met mainly from the harvested rainwater. Very small proportions of the people interviewed use water from hand dug wells and pipe borne water irrespective of the season of the year (Table 5). The situation is worse in the dry season when about eight in every ten persons interviewed now relied on the river/stream for their daily water needs, including drinking water. The proportions depending on these sources (river/stream, lake and ponds) increase as the numbers using harvested rainwater decrease. More people swim and bathe in the streams during the dry season than in the rainy season. Dependence on hand dug wells and pipe borne water remained very low. In Oko Amakom 1, the women expressed their dislike for water from other sources. According to some of them, "We go to Osei (River Niger) for all our water needs. That is what we were born to know. Our parents depended on it and nurtured us with it and that is what we know and will nurture our children with.

When asked about the hand dug well, the women chorused," Do you call that water? (and spat out). That is not water it is poison. Do you know that that water does not leather? When you pour it on your body, your body will form 'water-egg' giving the impression that you applied some jelly on your body before having the bath. Moreover it tastes terrible. The water from Osei does not have these problems at all. That is why we still use it for everything we do. We can go for swimming, washing and bathing without any regrets".

Age was a factor on the tendencies of the people to go swimming in the rivers/streams and pond in the different seasons. During the rainy and dry seasons, more of the younger persons 
go swimming in the river than the older persons $(P=0.013$ and 0.019) (Table 6). In the two cases, however, the strength of the association between age and tendencies to swim in the river was tested with the Pearson Coefficient of Contingency ' $c$ '. The results gave 0.19 and 0.18 for the rainy and seasons respectively. This showed that age makes more difference in the rainy season than in the dry season. Moreover, the Pearson Coefficient of Contingency scores are very low implying that age makes very little difference in the tendencies of the people to swim in the river. This shows that there is due to swimming in these communities irrespective of the age of the people. This definitely has implications for the transmission of the disease in the community.

Table 6: Distribution of respondents by some social characteristics and swimming in river during rainy or dry season (\% in parenthesis).

\begin{tabular}{|c|c|c|c|c|}
\hline \multirow{2}{*}{ Some Social Characteristics } & \multicolumn{2}{|c|}{ Swim in River } & \multirow{2}{*}{ Total } & \multirow[b]{2}{*}{ Statistical Significance } \\
\hline & Yes & No & & \\
\hline \multicolumn{5}{|l|}{ Rainy season } \\
\hline \multicolumn{5}{|l|}{ Sex } \\
\hline Male & $145(72.9)$ & $54(27.1)$ & $199(100)$ & Yates $_{\text {corrected }} \chi^{2}=0.12$ \\
\hline Female & $149(74.9)$ & $50(25.1)$ & $199(100)$ & $\mathrm{P}<0.0001$ \\
\hline \multicolumn{5}{|l|}{ Age group } \\
\hline $15-24$ & $86(82.7)$ & $18(17.3)$ & $104926.1)$ & \\
\hline $25-34$ & $47(61.0)$ & $30(39.0)$ & $77(19.3)$ & \\
\hline $35-44$ & $44(80.0)$ & $11(20.0)$ & $55(13.8)$ & $\chi^{2}=14.48$ \\
\hline $45-54$ & $44(75.9)$ & $14(24.1)$ & $58(14.6)$ & $\mathrm{P}=0.013$ \\
\hline $55-64$ & $31(77.5)$ & $9(22.5)$ & $40(10.1)$ & \\
\hline $65+$ & $42(65.6$ & $22(34.4)$ & $64(16.1)$ & \\
\hline \multicolumn{5}{|l|}{ Dry season } \\
\hline \multicolumn{5}{|l|}{ Sex } \\
\hline Male & $159(79.9)$ & $40(20.1)$ & $199(100)$ & Yates $_{\text {corrected }} \chi^{2}=0.08$ \\
\hline Female & $163(81.5)$ & $37(18.5)$ & $200(100)$ & $\mathrm{P}=0.78$ (Not significant \\
\hline \multicolumn{5}{|l|}{ Age group } \\
\hline $15-24$ & $92(87.6)$ & $13(12.4)$ & $105(28.3)$ & \\
\hline $25-34$ & $57(74.0)$ & $20(26.0)$ & $77(19.3)$ & $\chi^{2}=13.56$ \\
\hline $35-44$ & $46(83.6)$ & $9(16.4)$ & $55(13.8)$ & $\mathrm{P}=0.019$ \\
\hline $45-54$ & $51(87.9)$ & $7(12.1)$ & $58(14.5)$ & \\
\hline $55-64$ & $32(80.0)$ & $8(20.0)$ & $40(10.0)$ & \\
\hline $65+$ & $44(68.8)$ & $20(31.3)$ & $64(16.0)$ & \\
\hline
\end{tabular}

\section{Discussion}

In any control programme that is targeted at a disease with very low mortality the peoples' perception of their susceptibility to the disease, and the severity of the disease is important. The Health Belief Model (HBM) provides a useful framework for discussing the relationships between people's knowledge, perception and attitude to diseases on the one hand and their practices on such diseases (Rosenstock, 1974). The likelihood of taking a recommended action, in this case steps to prevent the transmission of Schistosomiasis haematobium according to the HBM model, would be directly influenced by beliefs about the threat of the disease (i.e. perceived severity and perceived susceptibility). These perceptions may be modified by social and demographic factors as well as knowledge. Perceived benefits and barriers may mediate intended action, while information from others could serve as cues to action (Brieger et al., 2007; Okeibunor et al., 2007a,b). This is supported by the assertion that transmission of schistosomiasis is the result of the interplay of biological, demographic, environmental and socioeconomic forces (Ximenes et al., 2001; Bruun \& Aagaard-Hensen, 2008).

In this study, very small proportions of the respondents perceive schistosomiasis as a serious disease. In fact, some of the participants in FGDs argued that since the disease does not harm the children nor prevent them from eating it is not serious. Some people in the quantitative study indicated that those infected with schistosomiasis are healthy and not sick. This shows a level of misconception that would not help the efforts to control the spread of the disease because the infected people will not do anything to seek effective treatment. It has been said that lack of knowledge is 
the main factor responsible for the high pitch level of schistosomiasis. Socio-demographic factors like age and sex, and even education did not influence the people's awareness of schistosomiasis. In this study, the level of endemicity was the main and only factor that affected awareness. Similarly, the attitude of the people to the disease was very poor and many exhibited misconceptions about the disease. For some it is a disease only for the males. Others opined that it is only the children who contract the disease, while yet other segments of the population hold that one can outgrow the disease. The attitudinal index showed that the various segments of the population had very poor attitude towards the disease. In many cases, the infection is left untreated because the people complained of the absence of effective treatment, but perhaps more importantly, because of the belief that one outgrows the infection. This is similar to the findings of Okeibunor et al. (1994) on factors associated with the use of salt sugar solution among mothers in Nsukka, Nigeria.

In this study, perception of personal susceptibility was found to be low, as most of the people either indicated that schistosomiasis is a disease of little children or for the other sex. The majority of people, in a sample where the females comprised more than $50 \%$, believed that it is a disease of males. Similarly, over three quarters of respondent thought schistosomiasis is a disease of children. This is likely to have implications for the desire to take steps to control the disease. Most individuals in an endemic community will not understand that they can be infected, and that there exists the need to receive treatment to reduce or eliminate transmission.

Particular causal explanations held by a community, be they perceived or real, will govern and shape the health beliefs concerning that illness. As revealed in this study, the causal explanations for schistosomiasis included witchcraft, body contact with an infected person, crossing the urine of a goat as well as the water they drink and sexual intercourse. Due also to the misconceptions, the adolescent girls conceal the infection. It was seen as a shameful condition, all of which do not contribute to the transmission of Schistosoma haematobium. Only very few respondents could associate schistosomiasis with the water contact activities in the communities. Amazigo et al. (1997) have demonstrated the impact of the duration spent in the river as well as the location of people to the water body on the transmission of urinary schistosomiasis. In this study, the people depend on the river for all their household water needs and swimming.

In conclusion, the study has identified a poor level of awareness about urinary schistosomiasis among communities of the Delta State in Nigeria. This poor level of awareness and knowledge about schistosomiasis will need to be addressed through intensive health education. Such an education campaign should focus on the cause and means of transmission as well as the consequences of untreated infections. The role of the vectors in the transmission of the disease should be emphasized.

\section{Acknowledgements}

The Carter Center/Nigeria provided technical and financial supports for this study.

Received 14 July 2009

Revised 15 February 2010

Accepted 27 September 2010

\section{References}

Amazigo, U.O., Anago-Amanze, C.I. \& Okeibunor, J.C. (1997) Urinary Schistosomiasis among schoolchildren in Nigeria: consequences of indigenous beliefs and water contact activities. Journal of Biosocial Science 29, 9-18.

Anosike, J.C., Nwoke, B.E.B. \& Njoku, A.J. (2001) The validity of haematuria in the community diagnosis of urinary schistosomiasis infections. Journal of Helminthology 75, 223-225.

Brieger, W.R., Okeibunor, J.C, Abiose, A., Wanji, S., Ndyomugyenyi, R., Elhassan, E. \& Amazigo, U.V. (2007) Feasibility of measuring compliance to annual ivermectin treatment in the african programme for onchocerciasis control. Tropical Medicine and International Health 12, 260-268.

Bruun, B. \& Aagaard-Hansen, J. (2008) The Social Context of Schistosomiasis and its Control. An Introduction and Annotated Bibliography. WHO/TDR.

Connolly, K.C. \& Kvalsvig, J.D. (1992) Infection, nutrition and cognitive performance in children. Parasitology 104, S187-S200.

Godin, G.D. \& Shepard, R.J. (1983) Physical fitness promotion programmes: effectiveness in modifying exercise behaviour. Canadian Journal of Applied Sports Service 8, 104113. 
Hopkins, D.R., Eigege, A., Miri, E.S., Gontor, I., Ogah, J., Umaru, J., Chuwang, C.G., Wanjira Mathai, M., Jinadu, Y., Amadiegwu, S., Oyenekan, K., Korve, K. \& Richards, F.O. Jr. (2002) Lymphatic filariasis elimination and schistosomiasis control in combination with onchocerciasis control in Nigeria. American Journal of Tropical Medicine and Hygiene 67, $266-272$.

Nokes, C. \& Bundy, D. (1993) Compliance and absenteeism in school children: implications for helminth control. Transactions of the Royal Society of Tropical Medicine and Hygiene 87, 148-152.

Nwaorgu, O.C., Okeibunor, J.C., Madu, E, Amazigo, U., Onyegegbu, N. \& Evans, D. (1998) A School-based schistosomiasis and intestinal helminthiasis control programme in Nigeria: acceptability to community members. Tropical Medicine and International Health 3, 842-849.

Obikeze, D.S. \& Okeibunor, J.C. (2002) Ageat-first marriage and fertility in Nigeria. International Journal of Contemporary Sociology 39, 135-147.

Okeibunor, J.C., Onyeneho, N., Chukwu, J.N., Post, E. (2007a) Where do tuberculosis patients go for treatment before reporting to DOTS clinics in southern Nigeria and why? Tanzania Health Research Bulletin 9, 94101.

Okeibunor J.C., Onyeneho, N., Chukwu, J.N. \& Post, E. (2007b). Barriers to care seeking in directly observed therapy short-course (DOTS) clinics and tuberculosis control in southern Nigeria: a qualitative analysis. International Quarterly of Community Health Education 27, 23-37.

Okeibunor, J.C., Asobie, F.C. \& Igboeli, C.C. (199495) Factors Associated with use of SSS among mothers in Nsukka Zone, Nigeria. International Quarterly of Community Health Education 15, 127-136.

Rosenstock, I.M. (1974) Historical origins of the health belief model. Health Education Monograph 2, 328.

Scott, C. \& Singh, S. (1981) Problems of data collection in the world fertility survey. In: World Fertility Survey Conference 1980: Record of Proceedings, Vol. III. Voorbug, Netherlands International Statistical Institute.

Stephenson, L.S. (1994) Helminth infections: a major factor in malnutrition. World Health Forum 15, 169-172.

Stephenson, L.S., Latham, M.C., Kinoti, S.Y., Kurz, K.M. \& Brigham, H. (1990) Improvement of physical fitness of Kenyan school boys infected with hookworm Trichuris trichuris trichiura and Ascaris lumbricoides following a single dose of albendazole. Transactions of the Royal Society of Tropical Medicine and Hygiene 84, 277-282.

WHO (1995) The Control of Schistosomiasis: Report of a WHO Expert Committee. Technical Reports Series 728.

Ximenes, R.A.A, Southgate, B., Smith, P.G., Neto, L.G. (2001) Social Environment Behaviour and Schistosomiasis in an Urban Population in the Northeast Brazil. Revista Panamericana de Salud Pubilca 9, 13-22. 